\title{
I CONCURSO MACIOHAL DE LETRAS JURÍDICAS
}

Laureados os Professores René Ariel Dotti e Alcides Munhoz Neło, da Fac. de Direito da UFPr.

O Governo do Estado do Paraná, por sua Secretaria da Justiça e o jornal matutino "Gazeta do Povo", numa iniciativa cultural que despertou vivo interesse em todo o País, realizaram o I Concurso Nacional de Letras Jurídicas.

Inscreveram-se 82 trabalhos monográficos, a saber:

N. ${ }^{\circ} 1$ - Sugestão ao Legislativo (Conjunto de Leis referentes ao Divórcio). N. $.^{\circ} 2-\mathrm{O}$ Direito de Proteção. N. ${ }^{\circ} 3-$ Da Assistência Litisconsorcial no Direito Processual Civil Brasileiro. N. ${ }^{\circ} 4$ - História do Pensamento Jurídico. N. ${ }^{\circ} 5$ - Comentários à Regulamentação do Divórcio no Brasil. N. 6 - O Drama da Codificação Civil no Império. N. ${ }^{\circ} 7-\mathrm{Da}$ Força Executiva da Duplicata não aceita, protestada e acompanhada de comprovante de entrega ou remessa de mercadoria. N. ${ }^{\circ} 8$ - Humanização da Pena. N. ${ }^{\circ} 9$ - A Teoria Vitimológica de Von Hentig: Perfil Estrutural. N. ${ }^{\circ} 10-0$ Direito de Propriedade e a Inconstitucionalidade da Denúncia Vazia. N. ${ }^{\circ} 11$ - Do Arrendamento Rural. N. ${ }^{\circ} 12$ - Da Prescrição no Direito do Trabalho. N. ${ }^{\circ} 13-$ A Forma de Citação da União e dos Estados-Membros na Ação de Usucapião. N. ${ }^{\circ}$ 14 - Do Julgamento do Agravo Retido no Primeiro Grau de Jurisdição. N. ${ }^{\circ} 15-\mathrm{Da}$ Inadmissibilidade dos Embargos de Terceiro Opostos pela Mulher Casada, Intimada da Penhora, à Execução Contra - Marido. N. ${ }^{\circ} 16$ - A Imposição da Valorização Imobiliária e a Contribuição de Melhoria. N. ${ }^{\circ} 17$ - A Ignorância da Antijuridicidade em Matéria Penal. N. ${ }^{\circ} 18$ - A Hipótese de Incidência como Sinal Normativo da Relação Jurídica Tributária. N. ${ }^{\circ} 19$ - Aspectos Jurídicos e Legais da Questão Ecológica. N. ${ }^{\circ} 20$ - A Presença da Mulher no Código Penal Brasileiro. N. ${ }^{\circ} 21$ - Verificação Judicial da Insalubridade e da Periculosidade. Como se Decidir no Caso de Divergência entre os Laudos do Perito e do Assistente Técnico. N. ${ }^{\circ} 22$ - Despojos Humanos. N. ${ }^{\circ} 23$ - Do Conceito do Direito. N. ${ }^{\circ} 24$ - Direito, Justiça e Polícia, em pauta musical. N. ${ }^{\circ} 25$ - Princípios Fundamentais do Processo Tributário Administrativo. N. ${ }^{\circ} 26$ - Fatores Determinantes 
da Delinqüência Feminina. N. ${ }^{\circ} 27$ - A Responsabilidade Jurídica do Cirurgião Plástico. N. ${ }^{\circ} 28$ - O fato llícito Dentro da Classificação dos Fatos Jurídicos. N. 29 - A Natureza do Direito de Resistência. N. ${ }^{\circ} 30$ - A Responsabilidade Civil do Construtor. N. ${ }^{\circ} 31$ - A Responsabilidade Civil do Advogado. N. ${ }^{\circ} 32$ - A Moderna S.A. no Brasil. N. ${ }^{\circ} 33$ - A Filosofia do Direito além da $3 .^{a}$ Dimensão. N. ${ }^{\circ} 34$ - Aspectos da Responsabilidade Civil. N. ${ }^{\circ} 35$ - A Constituição Mineira de 1891. N. ${ }^{\circ} 36$ - Retenção de Impostos Sobre Serviços na Fonte Pagadora Inconstitucionalidade e llegalidade de Lei Municipal. N. ${ }^{\circ} 37$ - Desapropriação. N. ${ }^{\circ} 38$ - Aspectos do Procedimento Sumaríssimo. N. ${ }^{\circ} 39-$ A Proteção da Vida Privada e a Liberdade de Informação. N. ${ }^{\circ} 40-0$ Trabalho para as Instituições Financeiras. N. ${ }^{\circ} 41$ - Direito Brasileiro da Propriedade: Limitações e Ingerências Administrativas. N. ${ }^{\circ} 42-$ A Decadência dos Princípios de Unidade e Universalidade dos Orçamentos Públicos. N. ${ }^{\circ} 43-O$ Condomínio Edilício e seus Problemas Atuais. N. ${ }^{\circ} 44$ - Aspectos da Inimputabilidade. N. ${ }^{\circ} 45$ - Medidas Jurídicas. N. ${ }^{\circ} 46$ - Estudos sobre o Cheque. N. ${ }^{\circ} 47$ - Notificação Necessária como Procedimento Cautelar Sujeito ao Prazo Preclusivo do Artigo 806 do CPC. N. ${ }^{\circ} 48$ - Compra e Venda e Sistemas de Transmissão da Propriedade. N. ${ }^{\circ} 49$ - O Interesse Público e sua Conceituação. N. ${ }^{\circ} 50$ - Referendum, Plebiscito, Recall, etc.. N. ${ }^{\circ} 51$ - A Paridade da Justiça do Trabalho. N. ${ }^{\circ} 52$ - "Seriam os Apóstolos Empregados de Cristo " N. ${ }^{\circ} 53$ - Direito Constitucional: Acumulação de Cargos e Funções Públicas. N. ${ }^{\circ} 54$ - Funcionário de Fato. N. ${ }^{\circ} 55-$ Plebiscito. N. ${ }^{\circ} 56$ - Questões sobre a Execução e os Embargos do Devedor. N. ${ }^{\circ} 57$ - A Esterilização Humana. N. ${ }^{\circ} 58$ - Das Funções Fundamentais da Interpretação do Direito. N. ${ }^{\circ} 59$ - Instrumentalidade, Paralelismo Normativo e Pragmatismo do Jurídico Permanente. N. ${ }^{\circ} 60$ - Definição Legal de Acidente do Trabalho. N. ${ }^{\circ} 61$ - Atos e Fatos Processuais. N. ${ }^{\circ} 62$ - $O$ Estado e a Formação dos Currículos Jurídicos no Brasil. N. ${ }^{\circ} 63$ - A Penhora nos Rostos dos Autos da Falência pela Fazenda Pública. N. ${ }^{\circ} 64$ - Tóxicos - Prevenção é a Meta. N. ${ }^{\circ} 65$ - Lei Nacional do Desenvolvimento Urbano. N. ${ }^{\circ} 66-$ Proteção Jurisdicional dos Direitos Humanos. N. ${ }^{\circ} 67$-- 0 Momento Sociológico Brasileiro e a Aferição da Imputabilidade Penal. N. ${ }^{\circ} 68$ Sobre um Direito de Autor do Domador de Animais. N. ${ }^{\circ} 69$ - A Crise das Instituições Brasileiras. N. ${ }^{\circ} 70$ - Regime Jurídico do Prefeito Nomeado. N. ${ }^{\circ} 71$ - Direitos e Deveres da Mulher. N. ${ }^{\circ} 72$ - Da Declaração de Inconstitucionalidade nos Tribunais e a Legislação Brasileira. N. 73 - O Direito Alfandegário no Brasil. N. ${ }^{\circ} 74$ - Das Sutilezas Jurídicas e suas Raízes Históricas. N. ${ }^{\circ} 75$ - O Problema da Eficácia do Direito. N. ${ }^{\circ} 76$ - Dos Efeitos da Irrevogabilidade do Mandato no Direito Civil Brasileiro. N. 77 - Os Princípios da Oralidade e da Economia Processual e o Julgamento Conforme o Estado do Processo. 
N. ${ }^{\circ} 78$ - Situação Jurídica, Unidade e Expressão do Fenômeno Jurídico. N. 79 - O Ato Administrativo. Sua Anulação e Efeitos Possessórios. N. ${ }^{\circ} 80$ - Comentários à Lei do Divórcio. N. ${ }^{\circ} 81$ - Direito Cooperativo, uma área a ser pesquisada. N. ${ }^{\circ} 82$ - A Vítima no Direito Brasileiro.

O concurso foi dirigido pela seguinte Camissão Executiva: Deputado Túlio Vargas, Secretário de Justiça do Paraná, e posteriormente substituído pelo novo secretário dr. José Maria de Azevedo; Dr. Francisco Cunha Pereira Filho, Diretor do Jornal Gazeta do Povo; Des. Guilherme de Albuquerque Maranhão, Procurador Geral da Justiça do Paraná; Dr. Lellis Antonio Correa, Procurador Geral do Estado do Paraná; Dr. Waterloo Marchesini Junior, Editor da Página Gazeta na Justiça; Dr. Antonio Celso Cavalcanti de Albuquerque, Editor da Página Gazeta da Justiça; Dr. Dilmar Abilio Archegas, Diretor Gerente da TV Paranaense Canal 12; Dr. David Wiedmer Neto, Assessor da Secretaria de Justiça do Paraná; e Dr. Goyá Campos, Assessor da Secretaria de Justiça do Paraná.

A Comissão Julgadora, que se reuniu em Curitiba no dia 23 de junho de 1978 para o fim de proferir o seu veredito, esteve integrada pelos juristas:

Altino Portugal Soares Pereira - Professor da Universidade Federal do Paraná, Ex-Consultor Geral do Estado do Paraná.

Ary Florêncio Guimarães - Professor da Universidade Federal do Paraná, Ex-Procurador Geral da Justiça do Paraná e ex-Consultor Geral do Estado, Desembargador aposentado do Tribunal de Justiça do Paraná.

Benjamin Moraes Filho - Professor da Universidade Federal do Rio de Janeiro, Autor dos anteprojetos do Cód. de Processo Penal, do Cód. de Execuções Criminais e da Lei de Contravenções Penais.

Elio Narézi - Advogado criminalista, Ex-Presidente da Ordem dos Advogados do Brasil, Seção do Paraná.

José Munhoz de Mello - Professor da Universidade Federal do Paraná, Ex-Desembargador Presidente do Tribunal de Justiça do Paraná, Presidente do Conselho Penitenciário do Paraná.

Miguel Reale - Professor da Universidade de São Paulo, Ex-Reitor da Universidade de São Paulo; Membro da Academia Brasileira de Letras.,

Miguel Seabra Fagundes - Desembargador aposentado do Trib. de Justiça do Rio Grande do Norte e ex-Ministro da Justiça. 
Oswaldo Trigueiro - Ex-Presidente do Supremo Tribunal Federal, Ex-Governador do Estado da Paraíba.

Washington de Barros Monteiro - Professor da Universidade de São Paulo, Desembargador aposentado do Tribunal de Justiça de São Paulo.

Ao autor do melhor trabalho classificado foi conferido o prêmio "Professor de Plácido e Silva", no valor de Cr\$100.000,00 (cem mil cruzeiros) e recaiu na pessoa do Prof. René Ariel Dotti, do Departamento de Direito Penal e Processual Penal da Faculdade de Direito da Universidade Federal do Paraná. Sua monografia versou o tema "A proteção da vida privada e a liberdade de informação". O autor paranaense melhor classificado fez jús ao prêmio "Professor Oscar Martins Gomes", no valor de Cr $\$ 50.000,00$ (cinqüenta mil cruzeiros) e coube ao Prof. Alcides Munhoz Netto, também integrante do referido Departamento universitário e que apresentou a monografia intitulada "A ignorância da antijuridicidade em matéria penal".

As menções honrosas, em número de cinco, laurearam os seguintes concorrentes: Sérgio Ferraz, do Rio de Janeiro ("Da assistência litisconsorcial no Direito Processual Civil Brasileiro"); Edson Ribas Malachini, do Estado do Paraná ("Questões sobre a execução e os embargos do devedor"); Sérgio Gisckon Pereira, de Pelotas, Estado do Rio Grande do Sul ("Aspectos do procedimento sumaríssimo"); Marco Antonio Gonçalves Torres, de Belo Horizonte, Estado de Minas Gerais ("A responsabilidade civil do advogado"): e Armando Henrique Dias Cabral, de Porto Alegre, Estado do Rio Grande do Sul ("Funcionário de fato").

Os professores René Ariel Dotti e Alcides Munhoz Neto são colaboradores assíduos da REVISTA DA FACULDADE DE DIREITO e merecem, sem dúvida, os aplausos do mundo cultural paranaense.

No dia 24 de agosto de 1978, no restaurante da Sociedade Helvethia, por iniciativa do Prof. Othela Werneck Lopes, Diretor do Setor de Ciências Sociais e Aplicadas da UFPr, foi realizado um jantar em homenagem aos Professores René Ariel Dotti e Alcides Munhoz Netto, do Departamento de Direito Penal e Processual Penal do Curso de Direito, vencedores, respectivamente, dos premios "Prof. De Plácido e Silva" e "Prof. Oscar Martins Gomes, do I Concurso Nacional de Letras Jurídicas.

Estiveram presentes, dentre professores, chefes de Departamentos e inúmeros amigos e admiradores dos homenageados, as seguintes autoridades do nosso mundo universitário e jurídico: 
Prof. Ocyron Cunha, Reitor da UFPr.; Desembargador Ariel Ferreira do Amaral e Silva, presidente do Tribunal de Justiça do Estado; Dr. José Maria de Azevedo, Secretário de Estado da Justiça do Governo do Paraná; Deputado Federal Tulio Vargas, ex-Secretário da Justiça; Deputado estadual dr. Francisco Accioly Rodrigues da Costa Neto; Desembargador Heliantho Guimarães Camargo, presidente do Tribunal Regional Eleitoral; Desembargador Zeferino M. Krukoski, Corregedor Geral da Justiça do Estado; Dr. João Cid de Macedo Portugal, presidente do Tribunal de Alçada do Paraná; Dr. Eduardo Rocha Virmond, presidente do Conselho da OAB no Paraná; Prof. Fernando Andrade de Oliveira, presidente do Instituto dos Advogados do Paraná; Juiz Abrahão Miguel, do Tribunal de Alçada do Estado; Dr. Francisco da Cunha Pereira Filho, diretor do jornal "Gazeta do Povo" e Dr. Alberto Manuel Pinto Gonçalves, Consul de Portugal no Paraná.

Durante o ágape, a que compareceram várias senhoras dos participantes, e transcorreu em ambiente de intensa cordialidade, o Prof. Othelo Werneck Lopes usou da palavra, inicialmente, para dizer dos motivos jubilosos que o levaram a promover a justa e oportuna homenagem aos dois juristas do Paraná, ambos formados e sedimentados na antiga e tradicional Faculdade de Direito de nossa Universidade, hoje alçados à posição de remarcado relevo no cenário cultural e jurídico do País, para gaudio de todos os paranaenses. E passou em seguida a palavra ao Prof. Antonio Acir Breda, do Departamento de Direito Penal e Processual Penal, credenciado para falar em nome do Setor. Disse o orador:

"Sempre que pensamos, fazemos o mundo em estilhaços. Mas também sempre, insensivelmente, logo vamos erguendo com eles, de novo, uma linda ponte" (Richard Dehmel).

Coube-me a honra de, em nome do Curso de Direito do Setor de Ciências Sociais Aplicadas da Universidade Federal do Paraná, falar na homenagem que hoje se presta aos professores René Ariel Dotti e Alcides Munhoz Neto, por terem ambos conquistado os dois primeiros lugares em concurso jurídico de âmbito nacional. Trata-se de uma justa homenagem a dois insígnes mestres da Ciência Penal, laureados em maratona cultural de grande projeção no País.

Sobejam razões para que os seus colegas da antiga Faculdade de Direito da Universidade Federal do Paraná aqui estejam reunidos, na companhia de amigos e familiares. A tradição iniciada com Ulisses Vieira, Clotário de Macedo Portugal, Laertes Munhoz e, depois, com o nosso caríssimo Ildefonso Marques, no estudo sério do Direito Penal, vem sendo mantida pelos homenageados, cuja projeção científica está definitivamente consolidada. 
Talvez tenha sido o escolhido pelo simples motivo de thes cultivar grande amizade e indisfarçável admiração. Fui aluno de René Dotti, no curso de bacharelado, dele aprendendo os primeiros passos na difícil arte da advocacia criminal. Passei a conviver com Alcides Munhoz Neto, primeiro na qualidade de amigo fraterno, depois, numa espécie de curso de aperfeiçoamento, como assistente eventual de suas magníficas lições na velha Faculdade de Direito.

Antes de enumerar toda a produção científica desses dois grandes professores, de relembrar o curriculum realmente invejável que possuem, permito-me alinhavar algumas palavras sobre o perfil comum de mestres do direito e de grandes advogados militantes.

Os dois possuem o espírito do estudante. Na definição de Goethe, estudante "é o que realiza um esforço constante". Em verdade, essa eterna tarefa é o signo de toda a cultura. Os homenageados, pelo estudo contínuo, pela pesquisa ininterrupta, "pelo esforço constante" adquiriram aquela qualidade difícil de ser alcançada: a do professor culturalmente equilibrado.

Especialistas do Direito Penal, sem o vício da dispersão excessiva, são homens de sólida formação cultural. Em suas obras, colocam como objetivo maior da humanidade o Homem e a preservação de suas liberdades fundamentais. Neste aspecto têm uma conduta rigorosamente igual: a luta por uma sociedade autenticamente democrática e livre, sedimentada no ideal de Justiça, uma vez que, na palavra vibrante de Del Vecchio, "sem ela, nem a vida seria possível, nem, se o fosse, mereceria ser vivida".

O equilíbrio cultural os leva a não transigir com o autoritarismo e a repelir qualquer sistema totalitário. Ambos comungam da mesma idéia de um dos personagens de Yolanda Földes, a grande escritora de "A rua do gato que pesca", segundo o qual: "a democracia é o único regime decente", porque engrandece o comportamento político e respeita a dignidade da pessoa humana.

Como mestres, se dedicam com amor ao ensino, essa gratificante missão de transmitir aos mais jovens a experiência e cultura dos mais velhos, vendo no aluno de hoje o futuro e competente profissional do amanhã. Mais do que isso, um aliado na luta pelo direito. Essa é uma conduta realmente dignificante. É preciso confiar na juventude, que não tem os nossos defeitos, mas pode adquirir as nossas virtudes. Tratam os jovens, não como o Pregador de Caldwell, a ver demônios incrustrados na alma humana, mas tendo presente a lição do Wilhelm Sauer: "A juventude é pura e sem mácula, como uma sublime obra de arte". 
Como advogados, Alcides Munhoz Neto e René Ariel Dotti são insuperáveis, aliando à grande cultura jurídica o exercício profissional correto e dedicado, sem receio de desagradar até mesmo os eventuais detentores do poder. Aqui servem de parâmetro àqueles que se iniciam na advocacia.

Por tudo isso, esses dois amigos e estimados professores merecem as nossas mais sinceras homenagens. O seu comportamento lembra a bela lição de Savigny: "Mais importante que todos os preceitos é o espíriło e a formação dos jurisłas".

Obrigado".

Os homenageados agradeceram a manifestação de que foram alvo. 